\title{
From Biophilia to Naturalist Intelligence Passing Through Perceived Restorativeness and Connection to Nature
}

\author{
Giuseppe Barbiero ${ }^{1,2 *}$ and Rita Berto ${ }^{1,3}$ \\ ${ }^{1}$ Affective Ecology Laboratory, University of Valle d'Aosta, Italy \\ ${ }^{2}$ IRIS-Interdisciplinary Research Institute on Sustainability, University of Torino, Italy \\ ${ }^{3}$ Department of Human Sciences, University of Verona, Italy
}

Submission: August 03, 2018; Published: August 23, 2018

"Corresponding author: Giuseppe Barbiero, Affective Ecology Laboratory, University of Valle d'Aosta, Strada Cappuccini, 2A-11100 Aosta, IT, Tel: +390165306768, Email: g.barbiero@univda.it

\begin{abstract}
This mini review looks at the affective bonds and the cognitive benefits at the basis of the relationship between human beings and Nature, as a solid starting point for an environmental education program aimed to foster naturalist intelligence. Evidences from studies of years of joint research in evolutionary biology and environmental psychology fields show a plausible overlapping between the constructs of Biophilia, Nature fascination and affiliation to life, and the measurable constructs of perceived restorativenesss and connection to Nature. Here we propose a theoretical model showing the role these constructs may play on the development of naturalist intelligence and eventually on pro-environmental behavior, i.e. the final aim of environmental education. In addition, a fresh speculation on the biophilic quality of the school environment as a way to sustain environmental education is proposed. Biophilia, as the evolutionary legacy, and naturalist intelligence, as the potential goal of education, can be considered the two poles of an environmental education journey where perceived restorativenesss and connection to Nature play a significant role.
\end{abstract}

Keywords: Biophilia; Biophilic quality; Naturalist intelligence; Perceived restorativeness; Connection to Nature

Abbreviations: BEH: Pro-environmental Behaviour; BQ: Biophilic Quality; BQI: Biophilic Quality Index; CN: Connection to Nature; EC: Environmental Concern; NI: Naturalist Intelligence and PR: Perceived Restorativeness

\section{Introduction}

According to E.O. Wilson biophilia is "the innately emotional affiliation of human beings to other living organisms" [1](p. 31). Wilson suggests that biophilia is a human trait that emerged following a spiral trajectory over time, typical of gene-culture coevolution, where "a certain genotype makes a behavioral response more likely, the response enhances survival and reproductive fitness, the phenotype consequently spreads through the population, and the behavioural response grows more frequent" [p. 33]. Later, Wilson refined the definition of biophilia, according to which it is "the innate tendency to focus upon life and lifelike forms and in some instances to affiliate with them emotionally" [1](p.134, our emphasis). This definition was an important step forward because on the one hand, it established a relationship between the Biophilia Hypothesis [3] and the Attention Restoration Theory [4,5] and on the other hand, it put biophilia within the more general perspective concerning Human-Nature ${ }^{1}$ [6]. Wilson suggested that biophilia consists of "a complex of learning rules that can be teased apart and analyzed individually" [1](p.31). To this end, here the components of biophilia, i.e., "focus upon" and "affiliation", are in the first place introduced separately, and then discussed together in order to highlight their joint contribution in the development of naturalist intelligence. In addition to that, the components of biophilia will be shown to easily correspond to two measurable and popular constructs in environmental psychology research: perceived restorativeness and connection to Nature, accomplishing Wilson's suggestion.

\section{Perceived restorativeness: the "focus upon life" of biophilia}

Why do human beings have an innate tendency "to focus upon life"? The answer is because of the fascination process [7], one of the four constructs of the Attention Restoration Theory [4]. Fascination corresponds to the feature of biophilia ${ }^{2}$ called

${ }^{1}$ In this paper "Nature" is written with a capital "N" to indicate the biosphere and the abiotic matrices (soil, air, water) where it flourishes and to avoid confusion with "nature" as the intrinsic quality of a certain creature and/or phenomenon. 
"focus upon" and it exactly is the engagement of the bottomup involuntary effortless attention, which typically occurs in natural environments [8]. Consistent with Kaplan's Fascination Hypothesis [4], eye movement research shows that the distraction inhibitory mechanism (which takes considerable effort but is necessary to directed attention to stay focused) is not engaged during the viewing of Nature scenes, instead, people shift easily from one feature to another [9]. Basically, when environmental patterns are fascinating, they contain little if any distraction and do not seem to require attention at all $[10,11]$. Accordingly, the activation of fascination is fundamental to recover from a state of mental fatigue, deriving exactly from the overuse of directed effortful attention $[4,12]$. To generate fascination in the observer is the most important characteristic, though not the only one ${ }^{3}$ of an environment to be perceived as restorative. According to the Biophilia Hypothesis [1] perceived restorativeness [13], people's ability to perceive the restorative value of the environment [14], could be traced back to our genetic predisposition to recognize in the natural environment "the" environment that allows a fast and deep psycho-physiological restoration $[15,16]$. Over the course of the past 200,000 years of Homo sapiens' evolution, natural selection has strongly shaped our characteristic features and among other things, humans could have also learnt that certain environments can aid recovery from attentional fatigue more than others [17]. It is plausible that to be able to restore attention in shorter time could have enhanced survival fitness and it would have conferred an evolutionary advantage [18] (p.181), [19] (p.104). From this standpoint, perceived restorativeness, understood as people's (measurable) ability to focus upon the environment restorative characteristic, could be one of the innate learning rules of biophilia [1](p.31).

\section{Connection to Nature: the "affiliation with life" of bio- philia}

The other feature of biophila called "affiliation" [2] (p.134) corresponds to the ability to create, in some circumstances, an emotional bond with life. In this way, "affiliation" could be seen as equivalent to the more popular (and measurable) construct "connectedness to Nature" [20], the experiential sense of oneness with the natural world. In contrast to perceived restorativeness, which is supposed to be a "state measure" because it varies in relation to the characteristics of the environment some literature shows connection to Nature to be a sort of consistent "trait measure": actually one feels connected to Nature or not regardless of where one is $[21,22]$. In this respect, Berto, Pasini and Barbiero found that children's perceived restorativeness increased during the course of a day experiencing a woodland environment, whereas their sense of connection to Nature did not; the authors drew two conclusions from this finding [23]. First, children's perceived restorativeness is a relatively immediate response to an environment, as recently shown also in Kuo, Browning and Penner's study where a similar restoration process was evocatively defined as "refueling students in flight" [24]. Second, even connection to Nature can vary but it takes longer time and meaningful experiences with the natural world. As a matter of fact, significant changes in connection to Nature can be obtained through frequent and direct exposure to Nature and a specific education planned to shape naturalist intelligence $[25,26]$.

\section{Naturalist Intelligence Can Be Nurtured by the Two Constructs of Biophilia}

The affective bonds (connection to Nature) and the attentional benefits (perceived restorativeness) at the basis of the relationship between human beings and Nature can be a solid starting point to foster naturalist intelligence. Howard Gardner defined naturalist intelligence as the ability "to recognize flora and fauna, to make other consequential distinctions in the natural world, and to use this ability productively" [27]. In the first place the construct was added to the original seven modalities of intelligence proposed by Gardner [28] and later integrated by Gardner himself in the Multiple Intelligences Theory [29] . At first, naturalist intelligence appears easy to encompass but is a quite complex construct. Although it consists of the ability to process information and to output environmental knowledge without including any emotional capacity [30], Gardner admits that in "exhibiting what Wilson has termed «biophilia», the naturalist intelligence is comfortable in the world of organisms and may well possess the talent of caring for, taming, or interacting subtly with various living creatures" [29] (p.49). The capacity of "caring for" and "interacting subtly" are manifestations of the awareness of having an affective and emotional bond with Nature and correspond to connection to Nature. Basically, naturalist intelligence feeds connection to Nature which, in turn, becomes deeper with the development of naturalist intelligence. At the same time, Gardner realizes that the "biographies of biologists routinely document an early fascination with plants and animals"[29]. Although no evidence of a relationship between perceived restorativeness and naturalist intelligence is available in literature, biologists' biographies show that what they call "early fascination" (here the fundamental component of perceived restorativeness) is crucial to the development of naturalist intelligence. Furthermore, sketches of biographies of famous naturalists - such as, for example, Rachel Carson [31] or

${ }^{2}$ Although biophobic responses are also part of human biophilia ( Ulrich, S.R., Biophilia, Biophobia, and Natural Landscapes. In The Biophilia Hypothesis. S.R. Kellert \& E.O. Wilson (Eds.) Washington, DC: Island Press, 1993, pp. 73-137), in this mini-review only the truly biophilic response will be considered, that is, the response that comes from a positive relationship with Nature.

${ }^{3}$ According to the ART [4] fascination, i.e. effortless-interest driven attention, is actually the main component of a restorative experience but it is not the only one, there are three other components that are likely to contribute to make an environment restorative: being-away (physical or psychological distance from everyday routine), extent (settings having scope and coherence that engage the mind and promote exploration), compatibility (environmental support for intended activities). Natural settings are liberally endowed with all of them and hence assessed as more restorative and preferred than urban/artificial environments. 
E.0. Wilson [32] show that an extensive naturalist intelligence enhanced their environmental concern which requiring more naturalist intelligence in return, at the same time motivated their pro-environmental behaviour. Recently, Berto and Barbiero [33] proposed a model showing the theoretical correlation between connection to Nature (CN), Perceived Restorativeness (PR),
Environmental Knowledge (EK), and Environmental Concern (EC) devised to highlight the role these cognitive and affective components have on pro-environmental behavior (BEH). Here we propose a revision of that model see (Figure 1) where EK is replaced by naturalist intelligence (NI) and PR is also proposed as a motivator for BEH [34].

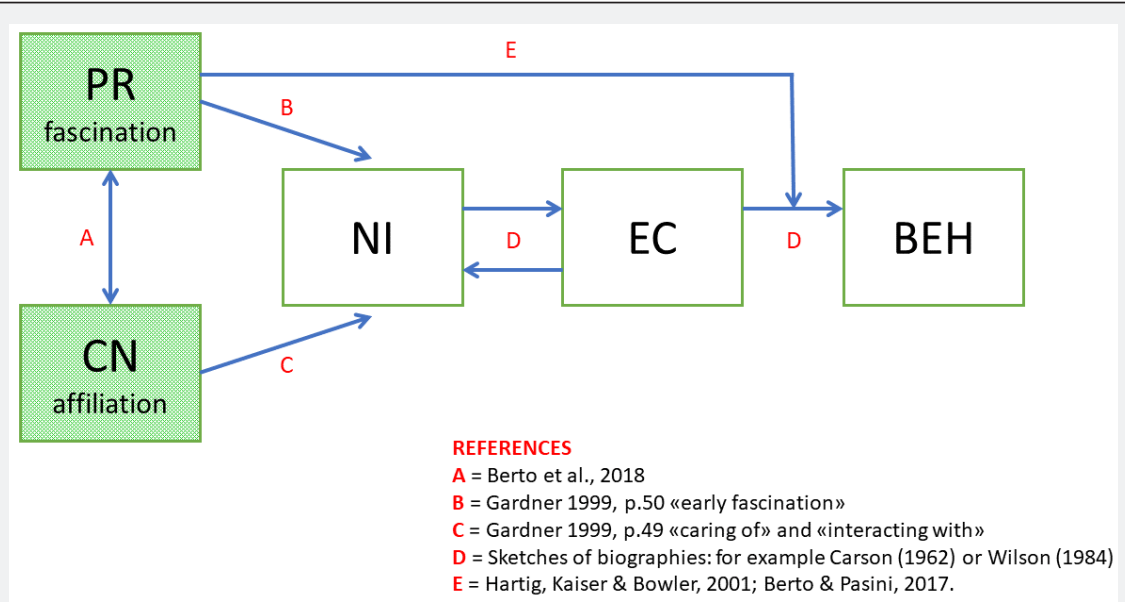

Figure 1: Hypothesized model where the two constructs of biophilia: fascination (PR) and affiliation $(C N)$ are put in relation with naturalist intelligence (NI), environmental concern (EC) and pro-environmental behaviour (BEH). Letters do not represent a temporal sequence, but only an internal bibliographic reference.

The biophilic quality of the environment to sustain environmental education

The development of naturalist intelligence in children, likewise the other forms of intelligence, requires the appropriate "environment" to be nurtured. Since naturalist intelligence deals literally with the environment, specifically with the natural one, it goes without saying that the main role in fostering this type of intelligence is played by the environment characteristics, in particular by its biophilic quality. The term biophilic quality (BQ) was recently introduced [35] and it roughly corresponds to all those physical, aesthetic and functional characteristics of an environment that from an evolutionary point of view contribute to make it "objectively" restorative bypassing an individual's assessment of restorativeness. In fact, BQI is centered on all aspects related to the restorative factors described in the ART (being away, fascination, extent, compatibility; see footnote 2) [4]. In a recent study [36] four parks were assigned with two different levels of $\mathrm{BQ}^{4}$ (low or high) according to the recreational opportunity they offered (see the recreational opportunity spectrum - ROS) [37] and the restorative potential of each setting. For each setting, the relationship between perceived restorativeness and connection to Nature was verified in visitors, in parallel with the park biophilic quality. What emerged was that when the setting was characterized by low BQ (e.g., an urban park) and the visitor had a low level of connection to Nature, the setting was perceived as highly restorative. In this case, the subject perceived only the "coarse" restorative aspects of the setting, corresponding to those best matching his/her expectations of the environment. On the contrary, when the visitor had a high level of connection to Nature, the same environment characterized by low $\mathrm{BQ}$, was perceived as low restorative. Only when the setting was characterized by high $\mathrm{BQ}$ (e.g., a natural reserve), the highly connected to Nature subjects perceived the high restorative potential of the setting. By the light of these results, here we try to outline how the biophilic quality can help environmental education to shape naturalist intelligence in children.

Let's begin by saying that to teach children acting proenvironmentally, whether locally or globally, is the final aim of environmental education. Pro-environmental behaviors arise from children's ability to perceive or infer information from the environment and to retain it as knowledge to be applied (as adaptive behaviors) to face environmental issues. Proenvironmental behavior sounds as a definition of naturalist intelligence suitable for the XXI century. However, there is a gap between the possession of environmental knowledge and displaying pro-environmental behaviors. In this regard, once Stephen J. Gould wrote: "we cannot win this battle to save species and environments without forging an emotional bond between ourselves and Nature as well-for we will not fight to save what we do not love" [38] (p.40). Biophilia is exactly our emotional bond with Nature and being innate in children it can be the most solid starting point to develop naturalist intelligence. Nevertheless,

${ }^{4}$ The biophilic quality level of an environment can be assessed with the Biophilic Quality Index (BQI). For more details see [35]. 
biophilia needs to be properly stimulated to nurture fascination and affiliation with Nature [33]. The environmental education task is exactly to "help" children to refine/sharpen their sensitivity/awareness to the natural world [39], through the socalled agoghé, a training regulated by specific learning objectives fitting child's age and the reached level of naturalist intelligence. However, beyond the ability to feel connected to Nature in all Its forms, a naturalist intelligent child possesses also the ability to recognize the setting that facilitates restoration from mental fatigue due to school activities, i.e. the environment with the "right" biophilic quality for him/her offering this opportunity. Likewise our ancestors, when the naturalist intelligent child recognizes the environments with high biophilic quality, he increases the fitness for survival. In this way, perceived restorativeness can be posited as a biophilic learning rule. If a high sense of connection to Nature allows recognizing the most biophilic and restorative environments, then feeling highly connected to Nature could represent an evolutionary advantage even for a modern child. The positive linear relation between PR and CN (the two constructs of biophilia where NI origins) which goes with the level of BQ (the objective restorative level of an environment) [36] shows that to shape NI in children, they need to attend a school environment where $\mathrm{CN}$ and PR are continuously kept alive through e.g. the biophilic design [40] Figure 2. The "restorative schoolroom" is turning out to be the right place to host environmental education, because the artificial indoor recalls the natural outdoor.
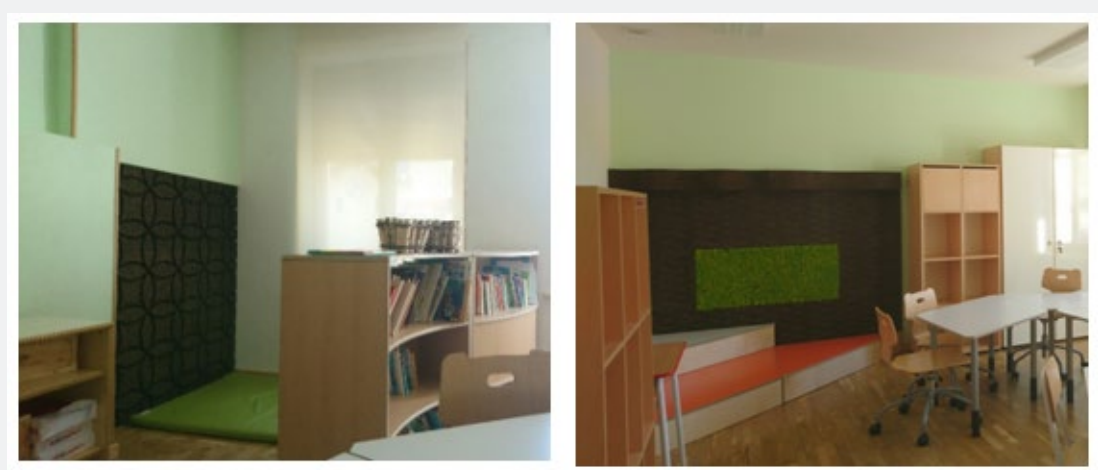

Figure 2: Pictures show the renovation of a regular classroom (rated low on the BQI) into a "restorative classroom" (rated high on the BQI). The "restorative schoolroom" is the explorative in progress work of Barbiero et al. [40] at the primary school at Gressoney-La-Trinité, Italy. Barbiero's project is aimed to highlight the role of the physical environment in sustaining environmental education. Specifically, the picture on the left depicts "the refuge" corner of the schoolroom where children can individually or in a small group benefit from a micro-restorative experience [41] the immersion experience is helped by the "wave like" bookshelf, the presence of a green cushion on the floor and of a corkoak wall. The picture on the right depicts "the prospect corner", here children standing or sitting down on steps can benefit from a different perspective of the schoolroom [42] to foster in children the experience of observing the schoolroom from the "outside", walls are covered by cork-oak where at the center a green insert smelling of real grass is present (Photos: Nicola Maculan).

\section{Concluding Remarks}

This mini-review aims to draw attention to a form of intelligence not so popular and usually neglected in formal education, though more and more necessary to face natural resources loss and preserve natural environment. From our standpoint, biophilia, as the evolutionary legacy, and naturalist intelligence, as the potential goal of education, can be considered the two poles of an environmental education journey $[43,16]$. The model we propose here offers a theoretical framework for environmental education that reflects children biophilic learning rules, i.e. the ground for connection to Nature and perceived restorativeness. Last but not least, perceived restorativeness and connection to Nature are measurable constructs, through the Perceived Restorativeness Scale [44,45,23], and the Connectedness to Nature Scale [20,23] accomplishing what Wilson suggested: the components of biophilia can be individually analyzed and measured. In fact, the measurability of the constructs implied within the conceptual framework "biophilia/naturalist intelligence" will allow the educator to plan the educational program ex-ante and to evaluate objectively the effect ex-post [40].

\section{Acknowledgements}

The authors wish to thank Martin Dodman who helped to arrange the manuscript.

\section{References}

1. Wilson EO (1993) Biophilia and the Conservation Ethic. In the Biophilia Hypothesis. Kellert SR, Wilson E (eds), Island Press, Washington DC, USA pp. 31-41.

2. Wilson EO (2002) The Future of Life. Alfred A Knopf, New York, NY, USA.

3. Kellert SR, Wilson EO (1993) The Biophilia Hypothesis. Island Press, Washington, USA.

4. Kaplan S (1995) The restorative effects of nature: Toward an integrative framework. Journal of Environmental Psychology 15(3): 169-182.

5. Barbiero G, Berto R (2016) Introduzione alla biofilia. La relazione con la Natura tra genetica e psicologia. Carocci, Roma, Italy, pp. 212.

6. Ives CD, Giusti M, Fischer J, Abson DJ, Christian DKK, et al. (2017) Human-nature connection: a multidisciplinary review. Curr Opin Environ Sustain 26-27: 106-113.

7. Berto R, Baroni MR, Zainaghi A, Bettella S (2010) An Exploratory Study of the Effect of High and Low Fascination Environments on Attentional Fatigue. J Environ Psychol 30(4): 494-500. 
8. Berto R, Barbiero G, Pasini M, Unema P (2015) Biophilic Design Triggers Fascination and Enhances Psychological Restoration in the Urban Environment. Journal of Bio urbanism 1,2: 27-34.

9. Berto R, Massaccesi S, Pasini M (2008) Do eye movements measured across high and low fascination photographs differ? Addressing Kaplan's fascination hypothesis. J Environ Psychol 28(2): 185-191.

10. James W (1892) Psychology: The Briefer Course, Holt: New York, NY, USA.

11. Berto R (2011) The Attentional Vantage Offered by Perceiving Fascinating Patterns in the Environment, In: Daniels JA (Ed), Advances in Environmental Research, vol 6, $4^{\text {th }}$ quarter. New York: Nova Science Publishers, pp. 503-516.

12. Berto R (2005) Exposure to restorative environments helps restore attentional capacity. Journal of Environmental Psychology 25(3): 249259.

13. Hartig T, Mang M, Evans GW (1991) Restorative effects of natural environments experience. Environment and Behavior 23(1): 3-26.

14. Purcell T, Peron E, Berto R (2001) Why do Preferences Differ between Scene Types? Environment and Behavior 33(1): 93-106.

15. Barbiero G (2011) Biophilia and Gaia. Two Hypotheses for an Affective Ecology. Journal of Bio urbanism 1: 11-27.

16. Barbiero G (2014) Affective Ecology for Sustainability. Visions for Sustainability 1: 20-30.

17. Berto R (2014) The Role of Nature in Coping with Psycho-physiological Stress. A Literature Review of Restorativeness. Behavioral Science 4 394-409.

18. Kaplan R, Kaplan S (1989) The Experience of Nature: A psychological perspective. Cambridge University Press, New York, NY, USA.

19. Kaplan S, Kaplan R (1983) Cognition and the environment. Functioning in an uncertain world. Ulrich's, Ann Arbor (MI), Michigan, USA

20. Mayer FS, McPherson Frantz CM (2004) The connectedness to nature scale. Journal of Environmental Psychology 24(4): 503-515.

21. Berto R (2007) Assessing the restorative value of the environment: A study on the elderly in comparison with young adults and adolescents. International Journal of Psychology 42(5): 331-341.

22. Mayer FS, McPherson Frantz CM (2009) Why is Nature Beneficial? The Role of Connectedness to Nature. Environment and Behaviour 41(5): 607-643.

23. Berto R, Pasini M, Barbiero G (2015) How does Psychological Restoration Work in Children? An Exploratory Study. J Child Adolesc Behav 3: 200.

24. Kuo M, Browning Mhem, Penner ML (2018) Do Lessons in Nature Boost Subsequent Classroom Engagement? Refueling Students in Flight. Front Psychol 8: 22-53.

25. Meyer M (1997) The Greening of Learning: Using the Eighth Intelligence. Educational Leadership 55(1): 32-34.

26. Nolan JL (2003) Multiple intelligences in the classroom. Education 124 (1): 115-119.
27. Gardner H (1995) Reflections on multiple intelligences: Myths and messages. Phi Delta Kappan 77: 200-209.

28. Gardner H (1983) Frames of mind: The theory of multiple intelligences. NY: Basic Books, New York, USA.

29. Gardner H (1999) Intelligence Reframed. NY: Basic Books, New York USA.

30. Gardner H, Moran S (2006) The Science of Multiple Intelligences Theory: A Response to Lynn Waterhouse. Educational Psychologist 41(4): 227-232.

31. Carson R (1962) Silent Spring. Houghton Mifflin, Boston MA, USA.

32. Wilson EO (1994) Naturalist. Island Press, Washington DC, USA.

33. Berto R, Barbiero G (2017) How the psychological benefits associated with exposure to Nature can affect pro-environmental behavior. Annals of Cognitive Science 1(1): 16-20.

34. Berto R, Pasini M (2017) Linked to Nature by Children, to Become Adults who Care for the Environment. Trasporti \& Cultura, monographic number Paesaggio e Psiche 46: 60-67.

35. Berto R, Barbiero G (2017) The Biophilic Quality Index. A Tool to Improve a Building from "Green" to Restorative. Visions for Sustainability 8: 38-45.

36. Berto R, Barbiero G, Barbiero P, Senes G (2018) Individual's Connection to Nature Can Affect Perceived Restorativeness of Natural Environments. Some Observations about Biophilia. Behav Sci 8(3): 34

37. Clark RN, Stankey GH (1979) The Recreation Opportunity Spectrum: A Framework for Planning, Managing and Research. US Department of Agriculture Forest Service, General Technical Report

38. Gould SJ (1993) Eight Little Piggies, Norton WW, New York.

39. Barbiero G, Marconato C (2016) Biophilia as Emotion. Visions for Sustainability 6: 45-51.

40. Barbiero G, Venturella A, Maculan N, Miroglio M, Berto R, Callegari G (2017) The Restorative Schoolroom of Gressoney-La-Trinité as an example of biophilic design integrated in energetic efficiency retrofit. Proceedings of the 27th Congress of The Italian Society of Ecology, Napoli, September 12-15, p.147.

41. Tennessen CM, Cimprich B (1995) Views to Nature effects on attention Journal of Environmental Psychology 15(1): 77-85.

42. Appleton J (1975) The experience of Landscape. NY: John Wiley \& Sons, New York, USA.

43. Barbiero G (2009) Revealing children's biophilia. In Science, society and sustainability: education and empowerment for an uncertain world. In: Gray D, et al. (Eds.), Milton Park, Routledge, UK, pp. 181-184.

44. Hartig T, Kaiser FG, Bowler P (2001) Psychological restoration in nature as a positive motivator for ecological behaviour. Environment and Behaviour 30(4): 590-607.

45. Pasini M, Berto R, Brondino M, Hall R, Ortner C (2014) How to Measure the Restorative Quality of Environments: The PRS-11. Procedia -Social and Behavioral Sciences 195: 293-297. 

(c) (9) ${ }_{\text {BY }}^{\text {This work is licensed under Creative }}$
Your next submission with Juniper Publishers will reach you the below assets

- Quality Editorial service

- Swift Peer Review

- Reprints availability

- E-prints Service

- Manuscript Podcast for convenient understanding

- Global attainment for your research

- Manuscript accessibility in different formats

( Pdf, E-pub, Full Text, Audio)

- Unceasing customer service

Track the below URL for one-step submission https://juniperpublishers.com/online-submission.php 